\title{
Bioactive calcium phosphate materials and applications in bone regeneration
}

\author{
Jiwoon Jeong ${ }^{1}$, Jung Hun Kim ${ }^{4}$, Jung Hee Shim³ ${ }^{3}$ Nathaniel S. Hwang ${ }^{1,4,5^{*}}$ and Chan Yeong Heo $1,2,3^{*}$
}

\begin{abstract}
Background: Bone regeneration involves various complex biological processes. Many experiments have been performed using biomaterials in vivo and in vitro to promote and understand bone regeneration. Among the many biomaterials, calcium phosphates which exist in the natural bone have been conducted a number of studies because of its bone regenerative property. It can be directly contributed to bone regeneration process or assist in the use of other biomaterials. Therefore, it is widely used in many applications and has been continuously studied.

Mainbody: Calcium phosphate has been widely used in bone regeneration applications because it shows osteoconductive and in some cases osteoinductive features. The release of calcium and phosphorus ions regulates the activation of osteoblasts and osteoclasts to facilitate bone regeneration. The control of surface properties and porosity of calcium phosphate affects cell/protein adhesion and growth and regulates bone mineral formation. Properties affecting bioactivity vary depending on the types of calcium phosphates such as HAP, TCP and can be utilized in various applications because of differences in ion release, solubility, stability, and mechanical strength. In order to make use of these properties, different calcium phosphates have been used together or mixed with other materials to complement their disadvantages and to highlight their advantages. Calcium phosphate has been utilized to improve bone regeneration in ways such as increasing osteoconductivity for bone ingrowth, enhancing osteoinductivity for bone mineralization with ion release control, and encapsulating drugs or growth factors.

Conclusion: Calcium phosphate has been used for bone regeneration in various forms such as coating, cement and scaffold based on its unique bioactive properties and bone regeneration effectiveness. Additionally, several studies have been actively carried out to improve the efficacy of calcium phosphate in combination with various healing agents. By summarizing the properties of calcium phosphate and its research direction, we hope that calcium phosphate can contribute to the clinical treatment approach for bone defect and disease.
\end{abstract}

Keywords: Calcium phosphate, Bone regeneration, Hydroxyapatite, Tricalcium phosphate, Whitlockite, Bone regenerative application

\section{Background}

Bone regeneration is intertwined with complex physiological processes by various materials and conditions [1], and interactions between environment conditions and substrates lead to a balance between osteoclasts and osteoblasts [2]. Bone regeneration has been extensively investigated in the clinical field using biomaterials. It is clinically complex and involves many biological processes. Numerous studies on areas such as the relationship between osteoclasts and osteoblasts, osteogenic

\footnotetext{
* Correspondence: nshwang@snu.ac.kr; lionheo@gmail.com

${ }^{1}$ Interdisciplinary Program in Bioengineering, Seoul National University, Seoul 152-742, Republic of Korea

Full list of author information is available at the end of the article
}

differentiation, stimulation effects of bone, cell growth, signaling pathways, and bone growth factors have been conducted in vitro and in vivo [2-4].

Biomaterials should be biologically stable and biocompatible in the body and elicit no immune response [5]. Materials used in clinical applications include polymers, metals, and carbon-based ceramics [6]. However, these materials show disadvantages such as poor mechanical properties, low biocompatibility, and poor adhesion to human tissues [7]. To overcome these issues, calcium phosphate-based ceramics, which are abundant in native human bone, have begun to emerge as suitable biomaterials [8]. Calcium phosphates have been reported to possess osteoconductive 
and osteoinductive characteristics, and they aid in the osteogenic differentiation of mesenchymal stem cells $[9,10]$. Therefore, many studies on the use of calcium phosphates for bone regeneration have been conducted, and applications in bone regeneration are actively being developed. In this review, we will summarize bone regenerative strategies using calcium phosphate by examining the bioactive properties and bone regenerative applications of calcium phosphate.

\section{Bioactivity of calcium phosphate}

Calcium phosphates are minerals composed of calcium cations and phosphate anions. They are known as the major inorganic material in approximately $60 \%$ of all native human bones (Table 1). The existence of calcium phosphates in bones was first discovered in 1769, and in the 1800s, calcium phosphates that exist in bones were subdivided into different categories (Fig. 1) [11, 12]. Since the 1900 s, synthetic calcium phosphates have been actively studied for clinical use [13-15]. Thereafter, bone regenerative applications such as bone cements, scaffolds, implants, and coating techniques using calcium phosphates have emerged, and some have been commercialized [16-18]. Similar to these, the characteristics of calcium phosphates have been studied for bone regenerative applications.

Every implantable material must be biocompatible, meaning that inflammation or foreign body response should not occur in the living system and tissue. Calcium phosphates were discovered to be biocompatible

Table 1 Typical compositional values of the inorganic phase of adult human calcified tissues [182]

\begin{tabular}{lllll}
\hline Composition & Enamel & Dentin & Bone & Hydroxyapatite \\
\hline Calcium [wt.\%] & 36.5 & 35.1 & 34.8 & 39.6 \\
Phosphorus [wt.\%] & 17.7 & 16.9 & 15.2 & 18.5 \\
Ca/P (molar ratio) & 1.63 & 1.61 & 1.71 & 1.67 \\
Sodium [wt.\%] & 0.5 & 0.6 & 0.9 & - \\
Magnesium [wt.\%] & 0.44 & 1.26 & 0.72 & - \\
Potassium [wt.\%] & 0.08 & 0.05 & 0.03 & - \\
Carbonate [wt.\%] & 3.5 & 5.6 & 7.4 & - \\
Fluoride [wt.\%] & 0.01 & 0.06 & 0.03 & - \\
Chloride [wt.\%] & 0.30 & 0.01 & 0.13 & - \\
Pyrophosphate & 0.022 & 0.10 & 0.07 & - \\
[wt.\%] & & & & \\
Total inorganic & 97 & 70 & 65 & 100 \\
[wt.\%] & & & & \\
Total organic [wt.\%] & 1.5 & 20 & 25 & - \\
Water [wt.\%] & 1.5 & 10 & 10 & - \\
$\begin{array}{l}\text { Ignition products } \\
\text { (800 }{ }^{\circ} \mathrm{C} \text { ) }\end{array}$ & $\beta-\mathrm{TCP}+$ & $\beta-\mathrm{TCP}+$ & $\mathrm{HAP}+$ & HAP \\
\hline
\end{tabular}

because they can be dissolved in body fluids and are present in large amounts in solid forms [19].

The properties of calcium phosphates affect bioactivity, such as adhesion, proliferation, and new bone formation in osteoblasts. To exhibit these bioactive features, degradation and ion release in calcium phosphates are important [19]. These phenomena increase the local concentration of calcium and phosphate ions and stimulate the formation of bone minerals on the surface of calcium phosphates. They also affect the expression of osteoblastic differentiation markers such as COL1, ALP, BMPs, OPN, OCN, BSP, ON, and RunX2 [20-24]. Calcium phosphates play important roles in cell adhesion and tissue formation by affecting the adsorption of extracellular matrix proteins on the surface $[25,26]$. Their properties also influence bone regeneration by affecting newly formed bone minerals [27].

First, calcium ions affect cells and living systems in several ways. Calcium is one of the ions that form the bone matrix, and it exists mostly in the form of calcium phosphates in bone tissues [28]. These calcium ions cause bone formation and maturation through calcification. In addition, calcium ions affect bone regeneration through cellular signaling. Calcium stimulates mature bone cells through the formation of nitric oxide and induces bone growth precursor cells for bone tissue regeneration [29, 30]. Calcium ions also stimulate the osteoblastic bone synthesis pathway by activating ERK1/2 [31] and increase the life span of osteoblasts by activating the PI3K/Akt pathways [32]. Furthermore, calcium ions regulate the formation and the resorptive functions of osteoclasts [33, 34].

Phosphorus ions are present in the human body in large amounts. They are involved in a variety of substances such as proteins, nucleic acid, and adenosine triphosphate, and they affect physiological processes $[35,36]$. Over $80 \%$ of phosphorous ions are present in bone in the form of calcium phosphates along with calcium ions. Phosphorous mainly exists in the form of phosphate $\left(\mathrm{PO}_{4}{ }^{3-}\right)$, which has great influence on tissue formation and growth [35]. Phosphate regulates the differentiation and growth of osteoblasts and the osteoblastic lineage via the IGF-1 and ERK1/2 pathways, and increases the expression of BMPs [37, 38]. In addition, phosphate has a negative feedback interaction between the RANK-ligand and its receptor signaling and regulates the ratio of RANK-ligand:OPG to inhibit osteoclast differentiation and bone resorption $[39,40]$.

The osteoinductive and osteoconductive features of calcium phosphates are also important for bone regeneration. Osteoinduction is the ability to induce progenitor cells to differentiate into osteoblastic lineages [41, 42], whereas osteoconduction is the ability of bone growth on the surface of materials [43]. Osteoinduction 


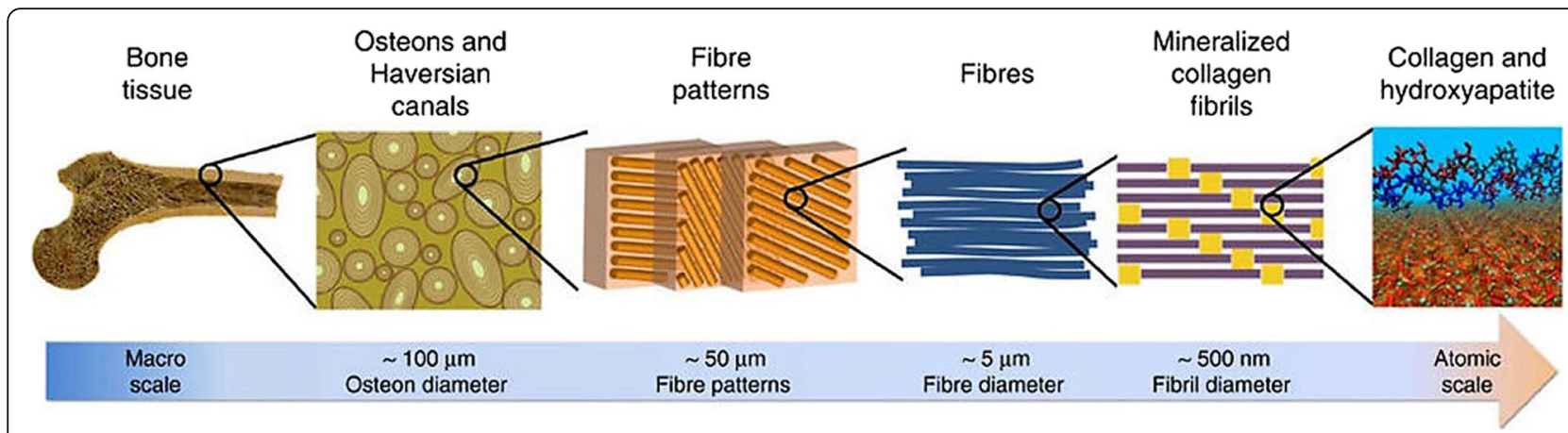

Fig. 1 Hierarchical structure of bone ranging from macroscale skeleton to nanoscale collagen and HAP [171]

and osteoconduction support cell adhesion and proliferation [41-43]. Cell adhesion is strongly influenced by the ability to adsorb extracellular matrix proteins. It is influenced by the surface characteristics of calcium phosphates, such as surface roughness, crystallinity, solubility, phase content, porosity, and surface energy [42].

Osteoconduction and osteoinduction depend on several factors. (Some studies suggested that calcium phosphates are osteoinductive even in the absence of supplements [42].) For example, surface chemistry and surface charge affect protein adsorption, and osteoblastic differentiation occurs via the interaction between cells and the extracellular matrix. Surface morphology can also exert these effects [42].

The role of the surface roughness of calcium phosphate is determined by the grain size and particle size of the calcium phosphate crystal structure. The roughness affects protein adhesion on the calcium phosphate surface. In general, protein adhesion improves at a roughness of less than $100 \mathrm{~nm}[44,45]$. Surface roughness also has an effect on cell adhesion [46].

The porosity of calcium phosphate also has an effect on bioactivity. The increase in porosity improves contact with body fluids on the surface area. Thus, dissolution rate is enhanced [19] and the presence of pores on the surface affects protein adsorption. It has been shown that protein adsorption is enhanced when the pore size of calcium phosphate was $20-500 \mu \mathrm{m}$ [47-49]. This effect was also observed with an increase in the number of pores. Additional, pore size impacts bone ingrowth and angiogenesis $[50,51]$. At a pore size of approximately $50 \mu \mathrm{m}$ or greater, ingrowth of blood vessels and bones was possible $[52,53]$. Pore sizes of greater than $100 \mu \mathrm{m}$ affect the mechanical strength and shape of calcium phosphate [54]. Because of the existence of pores, calcium phosphate exhibits mechanical properties such as high brittleness, low impact resistance, and low tensile stress [41]. However, its compressive strength is better than that of natural human bone, and it is used in non-load bearing implants, defect filling, and coating methods.
Hydrophilicity is a critical factor in osteogenesis regulation. Hydrophilic surfaces are essential for cell adsorption and increases fibroblastic cell response [55]. They increase the maturation and differentiation of bone cells as well as osteointegration, and they also affect cellular reactions [56, 57]. Moreover, surface hydrophilicity increases the adhesion and proliferation of osteoblasts [58, 59].

The dissolution process of calcium phosphates is affected by surface area per unit volume, fluid convection, acidity, and temperature $[19,41]$. This determines the stability and solubility of calcium phosphates and generally, solubility is inversely proportional to the ratio of $\mathrm{Ca} / \mathrm{P}$ ions, purity, crystal size, and surface area. Stable and low-solubility calcium phosphates show low ion exchange with their surroundings and slow recrystallization rate on the surface, thus determining protein concentration and conformation by electrostatic interaction at the charged site. On the other hand, calcium phosphates with high solubility easily change the local $\mathrm{pH}$ and ion concentration so that protein adhesion is affected. Protein adhesion causes cell adhesion and determines the effectiveness of bone regeneration [60-62].

\section{Types of calcium phosphates}

As mentioned above, the osteoconductivity and osteoinductivity of calcium phosphate comes from its physical/chemical characteristics. Therefore, it is important to control these characteristics and choose the calcium phosphates with properties that are appropriate for specific applications. Calcium phosphates with bioactive features in many crystalline phases have been studied (Fig. 2).

\section{Hydroxyapatite}

Hydroxyapatite (HAP) has been widely used in bone regeneration. It is a naturally occurring form of calcium phosphate that constitutes the largest amount of inorganic components in human bones [63]. The chemical 


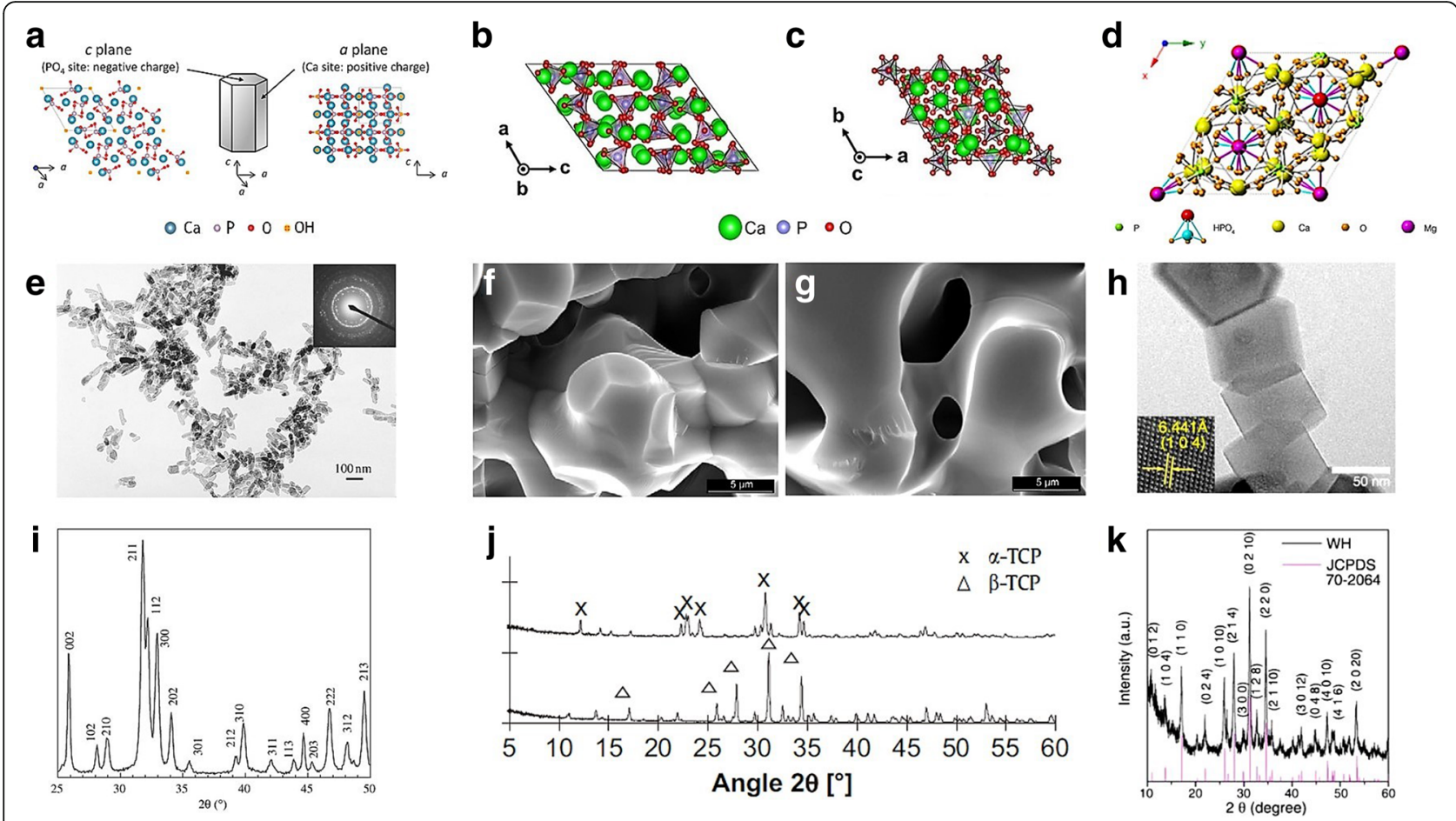

Fig. 2 Schematic illustration of the crystal structure of (a) HAP [172], (b) a-TCP, (c) $\beta-T C P$ [173], and (d) WH [114]. Copyright 2013 American Chemical Society. TEM and SEM images of (e) HAP [174], (f) a-TCP, (g) $\beta$-TCP [175], and (h) WH [117]. XRD data of (i) HAP [174], (j) a-TCP and $\beta$ TCP [175], and (k) WH [117]

formula of $\mathrm{HAP}$ is $\mathrm{Ca}_{10}\left(\mathrm{PO}_{4}\right)_{6}(\mathrm{OH})_{2}$ with a $\mathrm{Ca} / \mathrm{P}$ ratio of 1.67 [52, 64]. HAP is naturally formed and can be collected, but various ions and vacancies form defective structures. Therefore, HAP used in actual research or clinical applications is obtained by synthesis in aqueous solution systems [65]. Stoichiometric structures can have both monoclinic and hexagonal phases, but in biological environments, they take on a hexagonal phase, which is more stable structure [66, 67]. HAP is the most stable calcium phosphate with low solubility in physiological environments defined by temperature, $\mathrm{pH}$, body fluids, etc. [68, 69] and the surface of HAP can act as a nucleating site for bone minerals in body fluids [42, 70]. In addition, HAP does not cause inflammatory reactions when applied clinically [71].

HAP is known to be osteoconductive but not osteoinductive $[42,72]$. Therefore, ions such as fluoride, chloride, and carbonate ions are substituted as needed [73]. For example, the use of fluoride as an anionic substitution increased the stability and the use of magnesium as a cationic substitution increased the biological effect [42]. Studies have been conducted to utilize the biocompatible characteristics of HAP, showing that in vivo bone regeneration was improved with enhancing the differentiation or promoting the proliferation of mesenchymal stem cells by increased adhesion of osteoblasts $[74,75]$.
Research on the clinical applications of HAP in bone regeneration began in the mid-1980s. It has been used in implant coatings $[76,77]$ and graft materials $[78,79]$, and synthetic HAP has been studied in bone regenerative applications such as granules, cements, and pastes [80, 81]. Though HAP has been investigated for clinical applications, it has not been used in cases where high load is applied because of its unique hard and brittle properties, and it has been used mainly as coatings [66, 82]. For example, coatings on the surface of metallic implants have been prepared to improve osteoblast activity [83] or to increase the contact area of bone implants [84]. In this way, HAP coatings improved the biological fixation, biocompatibility, and bioactivity of implants [85]. In addition, deposition methods such as spraying, sputtering, pulsed laser deposition, and sol-gel techniques have been attempted, and several reports have been published whereby bone formation was promoted by increasing cellular response [86-88]. Furthermore, studies on bone regenerative applications have been carried out by mixing HAP with soft materials such as polymers to complement the drawbacks. Studies are underway to control the porosity, mechanical strength, bioactivity, and ease of use, mainly using synthetic scaffolds [89-91]. 


\section{Tricalcium phosphate}

Tricalcium phosphate (TCP; $\left.\mathrm{Ca}_{3}\left(\mathrm{PO}_{4}\right)_{2}\right)$, one of the most studied calcium phosphates along with HAP, is a calcium phosphate with a $\mathrm{Ca} / \mathrm{P}$ ratio of 1.5 and is divided into the $\alpha$-phase and $\beta$-phase. $\alpha$-TCP has the crystal structure of a monoclinic space group and $\beta$-TCP has the crystal structure of a rhombohedral space group [92, 93]. $\alpha$-TCP can be formed at $1125^{\circ} \mathrm{C}$ or higher, and $\beta$-TCP is formed at a temperature of $900-1100{ }^{\circ} \mathrm{C}[94,95]$. $\beta$-TCP has a more stable structure and higher biodegradation rate than those of $\alpha$-TCP. Therefore, $\beta$-TCP is generally used in bone regeneration [95]. $\beta$-TCP is less stable than HAP but has a faster degradation rate and higher solubility. In addition, it has a high resorption rate and is widely used to increase biocompatibility $[95,96]$. $\beta$-TCP promotes the proliferation of osteoprecursor cells such as osteoblasts and bone marrow stromal cells [97, 98]. These properties are due to the excellent biomineralization and cell adhesion by the nanoporous structure of $\beta$-TCP [99]. The characteristics of $\beta$-TCP have been actively studied for bone regeneration purposes, and $\beta$-TCP has been widely used in bone cements and bone substitution [100, 101].

In order to simultaneously utilize the characteristics of TCP and HAP, biphasic materials have been developed. Biphasic or multiphasic calcium phosphates exist in a form that is not separated because each component is homogeneously and intimately mixed at the submicron level [102]. The biphasic form of calcium phosphates was first prepared in 1986 as a mixture of HAP and $\beta$-TCP [103]. These biphasic calcium phosphates generally combine two more incompatible calcium phosphates, such as the more stable HAP and the more soluble TCP, and they have bene evaluated mainly in terms of bioactivity, bioresorbability, and osteoinductivity $[104,105]$. Biphasic calcium phosphates have been used and studied as bone grafts, bone substitute materials, and dental materials $[102,106]$. The mixture of HAP and $\beta$-TCP to stimulate the osteogenic differentiation of mesenchymal stem cells, increase cell adhesion, attach growth factors, and enhance mechanical properties has been actively carried out [107-109]. Ramay et al. [110] constructed a biodegradable porous nanocomposite scaffold containing a $\beta$-TCP matrix and HAP nanofibers. $\beta$-TCP/HAP scaffolds have been fabricated through gel-polymer methods and are expected to provide enhanced mechanical properties in load-bearing bone tissue engineering. The biphasic calcium phosphate scaffolds were found to have microporous structures that influenced cell growth and vascularization.

\section{Whitlockite}

Whitlockite (WH) is a calcium phosphate-based ceramic that contains a magnesium ion and has the chemical formula $\mathrm{Ca}_{9} \mathrm{Mg}\left(\mathrm{HPO}_{4}\right)\left(\mathrm{PO}_{4}\right)_{6}[111,112]$. WH is the second most abundant mineral in human bone, occupying approximately $25-35 \mathrm{wt} \%$ of the inorganic portion of human bone $[112,113]$. The $\mathrm{Ca} / \mathrm{P}$ ratio of $\mathrm{WH}$ is 1.43 and it has the crystal structure of the rhombohedral space group [112, 113]. WH has high stability at acidic conditions $(\mathrm{pH}<4.2)[114,115]$ and has a negatively charged surface [116]. Compared to HAP, WH showed mechanically higher compressive strength [117]. Its solubility was higher in physiological condition and higher amount of ions could be released continuously [116].

WH has been difficult to synthesize and thus, research on WH has not progressed well. However, as a result of recent advances, it has been possible to synthesize $\mathrm{WH}$ easily in low-temperature conditions. It has been reported that $\mathrm{WH}$ is formed when $\mathrm{Mg}$ ions are present in acidic solutions containing calcium phosphate [118]. In addition, in vivo formation of $\mathrm{WH}$ occurs under acidic conditions via the release of acidic molecules when osteoclasts resorb old bone $[119,120]$. Jang et al. [114] established a method for the stable formation of $\mathrm{WH}$, making it easy to obtain high-purity WH without any harmful byproducts. WH analysis showed a rhombohedral shape and WH nanoparticles with a diameter of $50 \mathrm{~nm}$ were obtained. WH induced higher expression of osteogenic genes than did HAP and $\beta$-TCP [117]. Moreover, in vivo bone regeneration of a rat calvarial defect model with composite hydrogel showed that WH promoted growth and osteogenic activity better than HAP did [116]. These results suggested that the continuous release of magnesium and phosphate ions promoted bone growth by controlling osteogenic differentiation. Especially, magnesium ions seemed to increase bone formation because they play a role in decreasing the activity of osteoclasts [121]. It has recently been shown that osteogenic activity was increased when WH and HAP coexisted at a ratio of approximately $1: 3$, a similar ratio to that in native human bone [122]. These results suggested that the roles and formation mechanisms of $\mathrm{WH}$ in native bone need to be studied. The high osteogenic activity of WH and its role in native bone are expected to contribute to future research on calcium phosphate materials.

In addition, octacalcium phosphate (OCP), which is present in human teeth $[123,124]$, has a triclinic crystal structure [125] and is considered to play a role in the initial phase of HAP formation in bone mineral formation [126, 127]. OCP plays a role as a precursor of bone mineralization [128] and showed high biocompatibility $[129,130]$. Thus, it has been extensively studied in bone implantation and coating $[131,132]$. The amorphous form of calcium phosphate [133] has been utilized in clinical applications where certain functions are 
performed through ion substitution and the use of various impurities [134, 135]. Similarly, several types of calcium phosphate-based materials have been studied and utilized.

Although the bioactive properties of calcium phosphate have been studied and used for bone regeneration, there are some drawbacks such as mechanical disadvantages in clinical applications. Therefore, research has been carried out to utilize calcium phosphate as composite materials with other materials.

\section{Applications of calcium phosphate}

Although calcium phosphate has been widely used for bone treatment as a raw material itself, many studies have been made using processed calcium phosphate applications for better utilization. It is used as coating materials for improving bioactivity of bone implants. And also, it is used as composites with biomaterials to alter mechanical properties, control biodegradability, and encapsulate drugs (Fig. 3).

\section{Coatings}

Calcium phosphate coatings can be applied to various materials to enhance bioactivity. Coating of calcium phosphate is mainly performed using sol-gel and electrodeposition methods [136, 137]. Research on calcium phosphate coatings is mainly conducted for metal implant applications, aiming to prevent implant corrosion and increase bioactivity [138, 139]. Xu et al. [140] investigated porous and net-like calcium phosphate $\left(\mathrm{CaHPO}_{4} \cdot 2 \mathrm{H}_{2} \mathrm{O}\right)$ layers coated on a magnesium alloy surface. This coating technology increased bioactivity, cytocompatibility, osteoconductivity, and osteogenesis. In vivo studies were conducted to compare this surface to that of conventional magnesium alloys. Experimental results showed that calcium phosphate-coated Mg alloy had significantly improved surface bioactivity. In the osteogenesis process, statistical differences in the expression of bone growth factor BMP- 2 and TGF- $\beta 1$ were observed compared to that on uncoated $\mathrm{Mg}$ alloys, resulting in more compact and uniform osteoid tissues.

In addition, studies on calcium phosphate coatings have resulted in improved surface reactivity and enhanced cell adhesion [141, 142]. Nguyen et al. [143] assessed the effectiveness of HAP surface coating for enhancing osteoconductivity in bone tissue engineering. They used Ti-6Al-4 $\mathrm{V}$ alloys with porous surfaces that were biocompatible in the human body. On top of this, a thin HAP surface was formed using a sol-gel coating technique to improve post-implantation bone ingrowth and osteoconductivity. HAP was coated on the porous surface of cylindrical implants. Using this alloy, in vivo testing of rabbit bone was carried out, and osteoconductivity was enhanced by increasing preferential protein adsorption.

Many studies have been conducted to encapsulate anti-bacterial agents and growth factors to enhance their

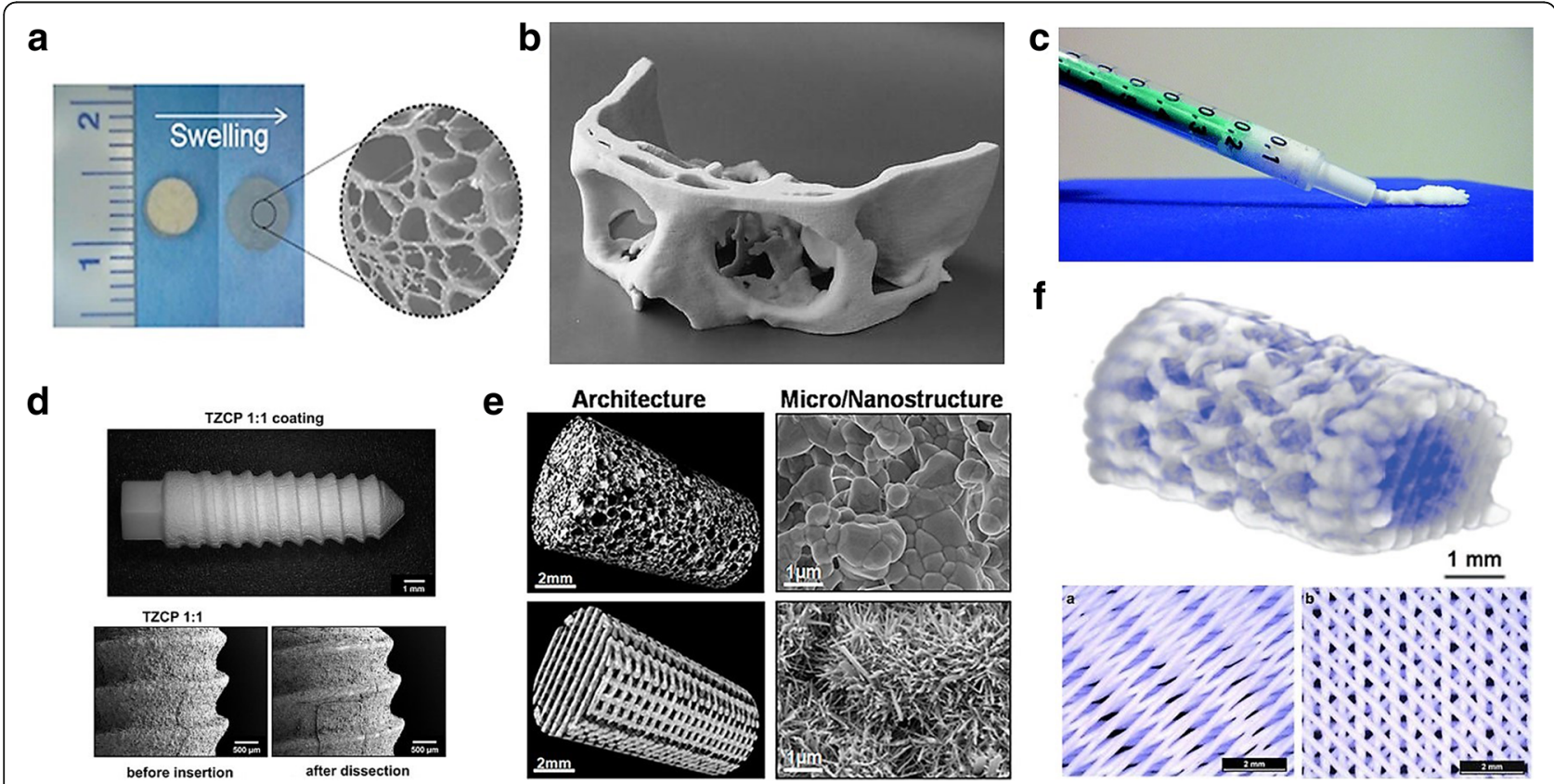

Fig. 3 Calcium phosphate based applications. (a) WH incorporated hydrogel scaffold [116, 176]. (b) Cranial segment made of tetracalcium phosphate and $\beta$-TCP [177]. (c) The injectable paste included calcium phosphate nanoparticles [178]. (d) Mixed zirconia calcium phosphate deposited on dental implant [179]. (e) 3D printed calcium-deficient HAP scaffolds [180]. (f) 3D printed calcium phosphate cement [181] 
effectiveness [144, 145]. To reduce infection and improve cell-material interaction and antimicrobial activity, $\mathrm{AgNO}_{3}$ and TCP were coated using the laser-engineered net shaping method on the surface of Ti metal by Roy et al. [146] Cytotoxicity assays were performed on human osteoblasts and bacterial adhesion was evaluated to assess bactericidal activity. The optimally controlled Ag-TCP-coated Ti showed a significant decrease in bacterial colonies.

\section{Cements}

Calcium phosphate cements are used to fill and heal bone defects. Cements are mainly incorporated with polymers such as alginate, chitin, chitosan, cellulose, gelatin, collagen, and synthetic polymers such as polyethylene glycol (PEG), poly (lactic-co-glycolic acid) (PLGA), polycaprolactone (PCL), and poly (L-lactic acid) (PLLA) [147]. As a composite of these polymers, calcium phosphate cements were able to control properties such as injectability, porosity, mechanical properties, and degradation rate [147]. Hesaraki et al. [148] looked at calcium phosphate cement with improved injectability and flow for use in the urethra in vesicoureteral reflux disease and minimally invasive surgery for bone defect repair. $\beta$-TCP pastes were mixed with hyaluronic acid or PEG to make calcium phosphate cement. The enhanced viscosity and thixotropy of the calcium phosphate cement were investigated and the effect on injectability was reported.

There are some problems of calcium phosphate cements such as the difference between bone regeneration rate and degradation rate, limit of ingrowth due to pore size, lack of mechanical strength, and inflammatory reaction of synthetic polymers. Efforts are continuously being made to overcome these problems $[149,150]$.

Much effort has been devoted to control pore size and improve mechanical strength [151], improve degradation rate by adjusting contact with body fluid [152], add materials to improve mechanical strength [153], and minimize foreign body response by using natural polymers [154, 155]. Studies are also conducted to increase the effectiveness of cements by encapsulating drugs and growth factors [156, 157]. PLGA and calcium phosphate complex compound cements prepared for sustained delivery of recombinant human bone morphogenetic protein-2 (rhBMP-2) were investigated by Ruhe et al. [158] In this study, the rhBMP-2 release effect was measured at different $\mathrm{pH}$ and nanostructure conditions, suggesting that this cement can be used for bone regeneration at ectopic or orthotopic sites. Ohura et al. prepared a mixed cement of monocalcium phosphate monohydrate (MCPM) and $\beta$-TCP as another effective carrier of rhBMP-2. rhBMP-2-transplanted $\beta$-TCP-MCPM showed good effect on bone regeneration as a carrier of rhBMP-2 with suitably controlled concentration.

\section{Scaffolds}

Calcium phosphate has been used in combination with scaffolds. Calcium phosphate scaffolds provide stable properties and allow the control of porosity and biocompatibility. The pore size of the scaffold improves revascularization and bone remodeling, enabling the ingrowth of cells and proteins and enhancing biocompatibility, making them suitable for implant use [89, $159,160]$. A variety of materials such as collagen, gelatin, PCL, PLGA, and PLLA can be used as scaffolding materials [89, 161-163]. Studies have been actively conducted to improve the bioactivity based on the characteristics and functions of various substances by enhancing the mechanical properties [164, 165], cell proliferation, and osteogenic differentiation [163, 166]. Zhao et al. [167] selected hydrogel scaffolds to improve bone regeneration. Calcium phosphates consisting of tetracalcium phosphate and dicalcium phosphate anhydrate were combined with alginate hydrogel microbeads encapsulating human umbilical cord mesenchymal stem cells to compensate for the lack of mechanical strength in the hydrogel for load-bearing. This combination could solve the difficulty in seeding cells deep within the scaffold and the inability of injection in minimally invasive surgeries. This alginate hydrogel scaffold was injectable and showed increased mechanical properties than those of conventional hydrogels.

Drugs and growth factors have been encapsulated within scaffolds [168, 169]. Koempel et al. [170] demonstrated that the integration of HAP in host bone can be promoted by attaching rhBMP-2 to macroporous ceramic HAP scaffolds. Scaffolds were implanted in rabbit calvarial defect models and after four weeks, the degree of bone formation was observed. rhBMP2-loaded implants showed more effective bone formation. In addition, rhBMP-2 was shown to enhance osteointegration, allowing HAP scaffolds to be held in place. Therefore, it was confirmed that BMP loaded on macroporous calcium phosphate scaffolds promoted new bone formation, prevented displacement, minimized host bone resorption, and decreased the incidence of infection and extrusion.

\section{Summary}

In summary, osteoconductive and osteoinductive features of calcium phosphate affect cell adhesion, proliferation, and new bone formation. Bioactivity can be altered and controlled by ion release and physical property of calcium phosphate on it. The ion release affects osteogenic cells, tissues, physiological processes and pathways. And then the physical property affects protein/cell absorption, promotes osteoblastic differentiation and osteointegration. Bioactive characteristics are different depending on the type of calcium 
phosphate such as HAP, TCP, and WH. These different bioactive characteristics are caused by the differences in $\mathrm{Ca} / \mathrm{P}$ ratio, crystal structure, stability, and solubility. As mentioned above, calcium phosphates are often used with other biomaterials to control and improve their properties. Various applications have been investigated, such as coating techniques, bone cements, and composite scaffolds that have been exploited to actively utilize the bioactive features of calcium phosphate in bone regeneration.

\section{Abbreviations}

Akt: Protein kinase B; ALP: Alkaline phosphatase; BMP: Bone-morphogenetic protein; BSP: Bone sialoprotein; COL1: Collagen type 1; ERK: Extracellular signal-regulated kinase; HAP: Hydroxyapatite; IGF: Insulin-like growth factor; MCPM: Monocalcium phosphate monohydrate; OCN: Osteocalcin; OCP: Octacalcium phosphate; ON: Osteonectin; OPG: Osteoprotegerin; OPN: Osteopontin; PCL: Polycaprolactone; PEG: Polyethylene glycol; PI3K: Phosphatidylinositol-3-kinase; PLGA: Poly (lactic-co-glycolic acid); PLLA: Poly (L-lactic acid); RANK: Receptor activator of nuclear factor kappa-B"; SEM: Scanning electron microscope; TCP: Tricalcium phosphate; TEM: Transmission electron microscopy; TGF: Transforming growth factor; WH: Whitlockite; XRD: X-ray diffraction spectroscopy

\section{Acknowledgements}

This work was supported by the Seoul National University Research Grant in 2017.

\section{Funding}

Not applicable.

\section{Availability of data and materials}

Not applicable.

\section{Authors' contributions}

The manuscript was mainly designed by $\mathrm{CYH}$ and JJ, and written through contributions of all authors. All authors read and approved the final manuscript.

\section{Ethics approval and consent to participate}

Not applicable.

\section{Consent for publication}

Not applicable.

\section{Competing interests}

The authors declare that they have no competing interests.

\section{Publisher's Note}

Springer Nature remains neutral with regard to jurisdictional claims in published maps and institutional affiliations.

\section{Author details \\ ${ }^{1}$ Interdisciplinary Program in Bioengineering, Seoul National University, Seoul 152-742, Republic of Korea. ${ }^{2}$ Department of Plastic and Reconstructive Surgery, College of Medicine, Seoul National University, Seoul, Republic of Korea. ${ }^{3}$ Department of Plastic and Reconstructive Surgery, Seoul National University Bundang Hospital, Seongnam, Republic of Korea. ${ }^{4}$ School of Chemical and Biological Engineering, Institute of Chemical Processes, Seoul National University, 1 Gwanak-ro, Gwanak-gu, Seoul 151-742, Republic of Korea. ${ }^{5} \mathrm{~N}$-Bio/BioMAX Institute, Seoul National University, Seoul 152-742, Republic of Korea.}

Received: 2 July 2018 Accepted: 7 December 2018 Published online: 14 January 2019

\section{References}

1. El-Ghannam A. Bone reconstruction: from bioceramics to tissue engineering. Expert Rev Med Devices. 2005;2:87-101.
2. Lemaire $V$, et al. Modeling the interactions between osteoblast and osteoclast activities in bone remodeling. JTBio. 2004;229:293-309.

3. Schliephake $\mathrm{H}$. Bone growth factors in maxillofacial skeletal reconstruction. IJOMS. 2002;31:469-84.

4. Checa S, Prendergast PJ. Effect of cell seeding and mechanical loading on vascularization and tissue formation inside a scaffold: a mechanobiological model using a lattice approach to simulate cell activity. JBiom. 2010;43:961-8.

5. Hulbert S, et al. Ceramics in surgery. Journal. 1983.

6. Hulbert S, et al. High tech ceramics, ed. P Vincenzini Journal. 1987.

7. Hench LL. Bioceramics: From concept to clinic. J Am Ceram Soc. 1991;74: 1487-510.

8. Kanazawa T, Umegaki T, Monma H. Apatites, New Inorganic Materials. Ceramics Japan. 1975;10:461-8.

9. Müller $\mathrm{P}$, et al. Calcium phosphate surfaces promote osteogenic differentiation of mesenchymal stem cells. J Cell Mol Med. 2008;12:281-91.

10. Shih Y-RV, et al. Calcium phosphate-bearing matrices induce osteogenic differentiation of stem cells through adenosine signaling. Proc Natl Acad Sci. 2014:111:990-5.

11. Nicholson W. A dictionary of practical and theoretical chemistry, in book a dictionary of practical and theoretical chemistry. London: R. Phillips; 1808.

12. Dana J. On the occurrence of fluor spar, apatite and chondrodite in limestone; 1846

13. Wells HG. Pathological calcification. The Journal of medical research. 1906;14:491.

14. Albee FH. Studies in bone growth: triple calcium phosphate as a stimulus to osteogenesis. Ann Surg. 1920;71:32

15. Schram W, Fosdick L. Stimulation of healing in long bones by use of artificial material. J Oral Surg. 1948;6:209.

16. Norman ME, et al. An in-vitro evaluation of coralline porous hydroxyapatite as a scaffold for osteoblast growth. Clin Mater. 1994;17:85-91.

17. Dekker $\mathrm{R}$, et al. Bone tissue engineering on calcium phosphate-coated titanium plates utilizing cultured rat bone marrow cells: a preliminary study. JMSMM. 1998:9.859-63.

18. Friedman $C D$, et al. BoneSource ${ }^{\mathrm{TM}}$ hydroxyapatite cement: a novel biomaterial for craniofacial skeletal tissue engineering and reconstruction. J Biomed Mater Res. 1998;43:428-32.

19. Ben-Nissan B. Advances in calcium phosphate biomaterials; 2014.

20. Frank $O$, et al. Real-time quantitative RT-PCR analysis of human bone marrow stromal cells during osteogenic differentiation in vitro. J Cell Biochem. 2002;85:737-46.

21. Shea JE, Miller SC. Skeletal function and structure: implications for tissuetargeted therapeutics. Adv Drug Del Rev. 2005;57:945-57.

22. Whited BM, et al. Osteoblast response to zirconia-hybridized pyrophosphate-stabilized amorphous calcium phosphate. J Biomed Mater Res A. 2006;76:596-604.

23. Komori T. Regulation of osteoblast differentiation by Runx2. in Osteoimmunology. Boston: Springer; 2009. p. 43-9.

24. Orimo $\mathrm{H}$. The mechanism of mineralization and the role of alkaline phosphatase in health and disease. J Nippon Med Sch. 2010;77:4-12.

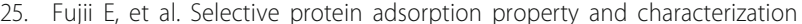
of nano-crystalline zinc-containing hydroxyapatite. Acta Biomater. 2006; 2:69-74.

26. Tsapikouni TS, Missirlis YF. Protein-material interactions: from micro-to-nano scale. Mater Sci Eng B. 2008:152:2-7.

27. Dorozhkin SV. Calcium orthophosphates. JMatS. 2007;42:1061-95.

28. Peacock M. Calcium metabolism in health and disease. Clin J Am Soc Nephrol. 2010;5:S23-30.

29. Foreman MA, et al. Group III metabotropic glutamate receptor activation inhibits $\mathrm{Ca} 2+$ influx and nitric oxide synthase activity in bone marrow stromal cells. J Cell Physiol. 2005;204:704-13.

30. Riddle RC, et al. MAP kinase and calcium signaling mediate fluid flowinduced human mesenchymal stem cell proliferation. American journal of physiology-cell. Physiology. 2006;290:C776-C84.

31. Liu D, et al. Activation of extracellular-signal regulated kinase (ERK1/2) by fluid shear is Ca2+-and ATP-dependent in MC3T3-E1 osteoblasts. Bone. 2008;42:644-52

32. Danciu TE, et al. Calcium regulates the PI3K-Akt pathway in stretched osteoblasts. FEBS Lett. 2003;536:193-7.

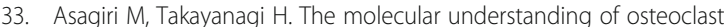
differentiation. Bone. 2007:40:251-64. 
34. Kuroda Y, et al. Osteoblasts induce Ca2+ oscillation-independent NFATc1 activation during osteoclastogenesis. Proc Natl Acad Sci U S A. 2008;105:8643-8.

35. Khoshniat $\mathrm{S}$, et al. The emergence of phosphate as a specific signaling molecule in bone and other cell types in mammals. Cell Mol Life Sci. 2011; 68:205-18.

36. Penido MGMG, Alon US. Phosphate homeostasis and its role in bone health. Pediatr Nephrol. 2012;27:2039-48.

37. Julien $M$, et al. Phosphate-dependent regulation of MGP in osteoblasts: role of ERK1/2 and Fra-1. J Bone Miner Res. 2009;24:1856-68.

38. Tada $\mathrm{H}$, et al. Phosphate increases bone morphogenetic protein-2 expression through CAMP-dependent protein kinase and ERK1/2 pathways in human dental pulp cells. Bone. 2011;48:1409-16.

39. Mozar A, et al. High extracellular inorganic phosphate concentration inhibits RANK-RANKL signaling in osteoclast-like cells. J Cell Physiol. 2008;215:47-54.

40. Zhang $\mathrm{R}$, et al. Unique roles of phosphorus in endochondral bone formation and osteocyte maturation. J Bone Miner Res. 2011;26:1047-56.

41. Ambard AJ, Mueninghoff L. Calcium phosphate cement: review of mechanical and biological properties. J Prosthodont. 2006;15:321-8.

42. Samavedi S, Whittington AR, Goldstein AS. Calcium phosphate ceramics in bone tissue engineering: a review of properties and their influence on cell behavior. Acta Biomater. 2013;9:8037-45.

43. Albrektsson T, Johansson C. Osteoinduction, osteoconduction and osseointegration. Eur Spine J. 2001;10:S96-S101.

44. Webster, T.J., et al. Specific proteins mediate enhanced osteoblast adhesion on nanophase ceramics. J Biomed Mater Res: an official journal of the Society for Biomaterials, the Japanese Society for Biomaterials, and the Australian Society for Biomaterials and the Korean society for Biomaterials 2000:51:475-483.

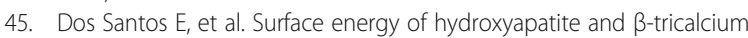
phosphate ceramics driving serum protein adsorption and osteoblast adhesion. JMSMM. 2008;19:2307-16.

46. Deligianni DD, et al. Effect of surface roughness of hydroxyapatite on human bone marrow cell adhesion, proliferation, differentiation and detachment strength. Biomaterials. 2000;22:87-96.

47. Rouahi M, et al. Physico-chemical characteristics and protein adsorption potential of hydroxyapatite particles: influence on in vitro biocompatibility of ceramics after sintering. Colloids Surf. B. Biointerfaces. 2006;47:10-9.

48. Li X, et al. The effect of calcium phosphate microstructure on bone-related cells in vitro. Biomaterials. 2008;29:3306-16.

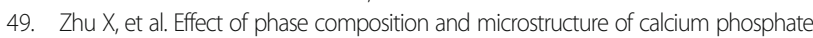
ceramic particles on protein adsorption. Acta Biomater. 2010;6:1536-41.

50. Mygind T, et al. Mesenchymal stem cell ingrowth and differentiation on coralline hydroxyapatite scaffolds. Biomaterials. 2007;28:1036-47.

51. Sakamoto M. Development and evaluation of superporous hydroxyapatite ceramics with triple pore structure as bone tissue scaffold. J Ceram Soc Jpn. 2010;118:753-7.

52. Dorozhkin SV, Epple M. Biological and medical significance of calcium phosphates. Angew Chem Int Ed. 2002;41:3130-46.

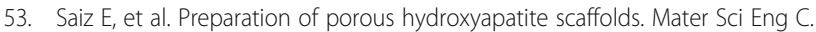
2007;27:546-50.

54. Sánchez-Salcedo S, Arcos D, Vallet-Regí M. Upgrading calcium phosphate scaffolds for tissue engineering applications, Journal Year. 377:19-42.

55. Aronov D, et al. Tunable hydroxyapatite wettability: effect on adhesion of biological molecules. Process Biochem. 2006;41:2367-72.

56. Eriksson C, Nygren H, Ohlson K. Implantation of hydrophilic and hydrophobic titanium discs in rat tibia: cellular reactions on the surfaces during the first 3 weeks in bone. Biomaterials. 2004;25:4759-66.

57. Zhao $\mathrm{G}$, et al. High surface energy enhances cell response to titanium substrate microstructure. J Biomed Mater Res A. 2005;74:49-58.

58. Anselme K. Osteoblast adhesion on biomaterials. Biomaterials. 2000;21:667-81.

59. Lim JY, et al. Systematic variation in osteoblast adhesion and phenotype with substratum surface characteristics. J Biomed Mater Res A. 2004;68:504-12.

60. Hu Q, et al. Effect of crystallinity of calcium phosphate nanoparticles on adhesion, proliferation, and differentiation of bone marrow mesenchymal stem cells. JMCh. 2007;17:4690-8.

61. Bodhak S, Bose S, Bandyopadhyay A. Role of surface charge and wettability on early stage mineralization and bone cell-materials interactions of polarized hydroxyapatite. Acta Biomater. 2009;5:2178-88.

62. Gustavsson J, et al. Osteoblast-like cellular response to dynamic changes in the ionic extracellular environment produced by calcium-deficient hydroxyapatite. JMSMM. 2012;23:2509-20.
63. Yoshikawa $H$, Myoui A. Bone tissue engineering with porous hydroxyapatite ceramics. J Artificial Organs. 2005;8:131-6.

64. Mouriño V, Boccaccini AR. Bone tissue engineering therapeutics: controlled drug delivery in three-dimensional scaffolds. J R Soc Interface. 2009: rsif20090379.

65. Markovic M, Fowler BO, Tung MS. Preparation and comprehensive characterization of a calcium hydroxyapatite reference material. J Res Natl Inst Stand Technol. 2004;109:553.

66. Calderin L, Stott M, Rubio A. Electronic and crystallographic structure of apatites. PhRvB. 2003:67:134106.

67. White TJ, Dong Z. Structural derivation and crystal chemistry of apatites Acta Crystallogr Sect B: Struct Sci. 2003;59:1-16.

68. Ramselaar $\mathrm{M}$, et al. Biodegradation of four calcium phosphate ceramics; in vivo rates and tissue interactions. JMSMM. 1991;2:63-70.

69. Rapacz-Kmita A, et al. FTIR and XRD investigations on the thermal stability of hydroxyapatite during hot pressing and pressureless sintering processes. JMoSt. 2005;744:653-6.

70. Bohner M, Lemaitre J. Can bioactivity be tested in vitro with SBF solution? Biomaterials. 2009;30:2175-9.

71. Patel $\mathrm{N}$, et al. A comparative study on the in vivo behavior of hydroxyapatite and silicon substituted hydroxyapatite granules. JMSMM. 2002;13:1199-206

72. Ogata K, et al. Comparison of osteoblast responses to hydroxyapatite and hydroxyapatite/soluble calcium phosphate composites. J Biomed Mater Res A. $2005 ; 72: 127-35$.

73. Huang J, et al. In vitro evaluation of nanosized carbonate-substituted hydroxyapatite and its polyhydroxyethylmethacrylate nanocomposite. J Biomed Mater Res A. 2008:87:598-607.

74. Douglas T, et al. Porous polymer/hydroxyapatite scaffolds: characterization and biocompatibility investigations. JMSMM. 2009;20:1909-15.

75. Guo H, et al. Biocompatibility and osteogenicity of degradable ca-deficient hydroxyapatite scaffolds from calcium phosphate cement for bone tissue engineering. Acta Biomater. 2009;5:268-78.

76. Capilla MV, et al. Cylindrical dental implants with hydroxyapatite-and titanium plasma spray-coated surfaces: 5-year results. J Oral Implantol. 2007; 33:59-68.

77. Zhou W, et al. Long-term survivability of hydroxyapatite-coated implants: a meta-analysis. Oral Surg. 2011:4:2-7.

78. Hallman M, et al. A 3-year prospective follow-up study of implant-supported fixed prostheses in patients subjected to maxillary sinus floor augmentation with a 80: 20 mixture of deproteinized bovine bone and autogenous bone: Clinical, radiographic and resonance frequency analysis. IJOMS. 2005;34:273-80.

79. Rumpel $\mathrm{E}$, et al. The biodegradation of hydroxyapatite bone graft substitutes in vivo. Folia Morphol (Praha). 2006;65:43-8.

80. Mendonça $\mathrm{G}$, et al. Advancing dental implant surface technology-from micron-to nanotopography. Biomaterials. 2008;29:3822-35.

81. Beachley $V$, Wen X. Polymer nanofibrous structures: fabrication, biofunctionalization, and cell interactions. Prog Polym Sci. 2010;35:868-92.

82. Dey A, et al. Characterization of microplasma sprayed hydroxyapatite coating. JTST. 2009;18:578-92.

83. Ramires $\mathrm{P}$, et al. Biological behavior of sol-gel coated dental implants. JMSMM. 2003;14:539-45.

84. Darimont $\mathrm{G}$, et al. In vivo behaviour of hydroxyapatite coatings on titanium implants: a quantitative study in the rabbit. Biomaterials. 2002;23:2569-75.

85. Albrektsson T. Hydroxyapatite-coated implants: a case against their use. JOMS. 1998;56:1312-26.

86. de Oliveira PT, et al. Enhancement of in vitro osteogenesis on titanium by chemically produced nanotopography. J Biomed Mater Res A. 2007;80:554-64.

87. Göransson A, et al. An in vitro comparison of possibly bioactive titanium implant surfaces. J Biomed Mater Res A. 2009:88:1037-47.

88. Yoshimoto $\mathrm{R}$, et al. Effects of functionally graded hydroxyapatite for large mandibular defects in adult rabbits. Journal of hard tissue biology. 2010;19:33-42.

89. Hwang NS, et al. Biomaterials directed in vivo osteogenic differentiation of mesenchymal cells derived from human embryonic stem cells. Tissue Eng A. 2013;19:1723-32.

90. Dhivya S, et al. Nanohydroxyapatite-reinforced chitosan composite hydrogel for bone tissue repair in vitro and in vivo. Journal of nanobiotechnology. 2015:13:40.

91. Thorpe A, et al. Hydroxyapatite nanoparticle injectable hydrogel scaffold to support osteogenic differentiation of human mesenchymal stem cells. European Cells and Materials. 2016;32:1-23. 
92. Dickens B, Schroeder L, Brown W. Crystallographic studies of the role of mg as a stabilizing impurity in $\beta-\mathrm{Ca} 3$ (PO4) 2. The crystal structure of pure $\beta$ Ca3 (PO4) 2. J Solid State Chem. 1974;10:232-48.

93. Mathew $\mathrm{M}$, et al. The crystal structure of a-Ca3 (PO4) 2. Acta Crystallogr B Struct Crystallogr Cryst Chem. 1977;33:1325-33.

94. Yubao L, Xingdong Z, De Groot K. Hydrolysis and phase transition of alphatricalcium phosphate. Biomaterials. 1997;18:737-41.

95. Horch $\mathrm{H}-\mathrm{H}$, et al. Synthetic, pure-phase beta-tricalcium phosphate ceramic granules (Cerasorb ${ }^{\circledR}$ ) for bone regeneration in the reconstructive surgery of the jaws. IJOMS. 2006;35:708-13.

96. Yamada $\mathrm{S}$, et al. Osteoclastic resorption of calcium phosphate ceramics with different hydroxyapatite/ $\beta$-tricalcium phosphate ratios. Biomaterials. 1997;18:1037-41.

97. Yao $\mathrm{CH}$, et al. Biocompatibility and biodegradation of a bone composite containing tricalcium phosphate and genipin crosslinked gelatin. J Biomed Mater Res A. 2004;69:709-17.

98. Liu H, et al. $\beta$-Tricalcium phosphate nanoparticles adhered carbon nanofibrous membrane for human osteoblasts cell culture. MatL. 2010;64:725-8.

99. Kamitakahara M, Ohtsuki C, Miyazaki T. Behavior of ceramic biomaterials derived from tricalcium phosphate in physiological condition. J Biomater Appl. 2008;23:197-212

100. Bi L, et al. Reconstruction of goat tibial defects using an injectable tricalcium phosphate/chitosan in combination with autologous platelet-rich plasma. Biomaterials. 2010;31:3201-11.

101. Luginbuehl V, et al. Controlled release of tetracycline from biodegradable $\beta$ tricalcium phosphate composites. J Biomed Mater Res B Appl Biomater. 2010;92:341-52

102. Dorozhkin SV. Biphasic, triphasic and multiphasic calcium orthophosphates. Acta Biomater. 2012;8:963-77.

103. Ellinger RF, Nery E, Lynch K. Histological assessment of periodontal osseous defects following implantation of hydroxyapatite and biphasic calcium phosphate ceramics: a case report. Int J Periodontics Restorative Dent. 1986;6:22.

104. Daculsi G. Biphasic calcium phosphate concept applied to artificial bone, implant coating and injectable bone substitute. Biomaterials. 1998;19:1473-8.

105. Lobo SE, Livingston Arinzeh T. Biphasic calcium phosphate ceramics for bone regeneration and tissue engineering applications. Materials. 2010; 3:815-26.

106. Daculsi G, Baroth S, LeGeros R. 20 years of biphasic calcium phosphate bioceramics development and applications. In: Advances in Bioceramics and Porous Ceramics II; 2010. p. 45-58.

107. Arinzeh TL, et al. A comparative study of biphasic calcium phosphate ceramics for human mesenchymal stem-cell-induced bone formation. Biomaterials. 2005;26:3631-8.

108. Amirian J, et al. Bone formation of a porous gelatin-pectin-biphasic calcium phosphate composite in presence of BMP-2 and VEGF. Int J Biol Macromol. 2015;76:10-24

109. He F, et al. Comparative study on in vivo response of porous calcium carbonate composite ceramic and biphasic calcium phosphate ceramic. Mater Sci Eng C. 2016;64:117-23.

110. Ramay HR, Zhang M. Biphasic calcium phosphate nanocomposite porous scaffolds for load-bearing bone tissue engineering. Biomaterials. 2004;25:5171-80.

111. Scotchford CA, Vickers M, Ali SY. The isolation and characterization of magnesium whitlockite crystals from human articular cartilage. OsCar. 1995; 3:79-94.

112. Elliott JC. Structure and chemistry of the apatites and other calcium orthophosphates, in book structure and chemistry of the apatites and other calcium orthophosphates: Elsevier; 2013.

113. Driessens FC, Verbeeck R. Biominerals. Florida: CRC press; 1990.

114. Jang $H L$, et al. Revisiting whitlockite, the second most abundant biomineral in bone: nanocrystal synthesis in physiologically relevant conditions and biocompatibility evaluation. ACS Nano. 2013;8:634-41.

115. Jang $\mathrm{HL}$, et al. Phase transformation from hydroxyapatite to the secondary bone mineral, whitlockite. J Mater Chem B. 2015;3:1342-9.

116. Kim HD, et al. Biomimetic whitlockite inorganic nanoparticles-mediated in situ remodeling and rapid bone regeneration. Biomaterials. 2017;112:31-43.

117. Jang $\mathrm{HL}$, et al. In vitro and in vivo evaluation of Whitlockite biocompatibility: comparative study with hydroxyapatite and $\beta$-Tricalcium phosphate. Advanced healthcare materials. 2016:5:128-36.

118. Cheng P-T, Grabher J, LeGeros R. Effects of magnesium on calcium phosphate formation. Magnesium. 1988;7:123-32.
119. Silver I, Murrills R, Etherington D. Microelectrode studies on the acid microenvironment beneath adherent macrophages and osteoclasts. Exp Cell Res. 1988;175:266-76.

120. Teitelbaum SL. Bone resorption by osteoclasts. Sci. 2000;289:1504-8.

121. Kim HK, et al. Comprehensive study on the roles of released ions from biodegradable mg-5 wt $\%$ ca- 1 wt $\%$ Zn alloy in bone regeneration. J Tissue Eng Regen Med. 2017;11:2710-24.

122. Cheng $H$, et al. Synergistic interplay between the two major bone minerals, hydroxyapatite and whitlockite nanoparticles, for osteogenic differentiation of mesenchymal stem cells. Acta Biomater. 2018;69:342-51.

123. Zapanta Le Geros R. Variations in the crystalline components of human dental calculus: I. crystallographic and spectroscopic methods of analysis. J Dent Res. 1974:53:45-50.

124. Chow LC, Eanes ED. Octacalcium phosphate. Vol. 18. Basel: Karger medical and scientific publishers; 2001.

125. Barrère F, van Blitterswijk CA, de Groot K. Bone regeneration: molecular and cellular interactions with calcium phosphate ceramics. Int J Nanomedicine. 2006;1:317.

126. Steuer $P$, Voegel J-C, Cuisinier F. First experimental evidence for human dentine crystal formation involving conversion of octacalcium phosphate to hydroxyapatite. Acta Crystallogr Sect D Biol Crystallogr. 1998;54:1377-81.

127. Suzuki $\mathrm{O}$, et al. Bone regeneration by synthetic octacalcium phosphate and its role in biological mineralization. Curr Med Chem. 2008;15:305-13.

128. Barrere F, et al. Biomimetic coatings on titanium: a crystal growth study of octacalcium phosphate. JMSMM. 2001;12:529-34.

129. Socol G, et al. Biocompatible nanocrystalline octacalcium phosphate thin films obtained by pulsed laser deposition. Biomaterials. 2004;25:2539-45.

130. Shelton R, et al. Bone marrow cell gene expression and tissue construct assembly using octacalcium phosphate microscaffolds. Biomaterials. 2006;27: 2874-81.

131. Kikawa T, et al. Intramembranous bone tissue response to biodegradable octacalcium phosphate implant. Acta Biomater. 2009;5:1756-66.

132. Stefanic $M$, et al. Rapid biomimetic deposition of octacalcium phosphate coatings on zirconia ceramics (Y-TZP) for dental implant applications. ApSS. 2012;258:4649-56.

133. Ter Brugge PJ, Wolke JG, Jansen JA. Effect of calcium phosphate coating composition and crystallinity on the response of osteogenic cells in vitro. COIR. 2003:14:472-80.

134. Combes C, Rey C. Amorphous calcium phosphates: synthesis, properties and uses in biomaterials. Acta Biomater. 2010;6:3362-78.

135. Popp JR, et al. Fabrication and characterization of poly (lactic-co-glycolic acid) microsphere/amorphous calcium phosphate scaffolds. J Tissue Eng Regen Med. 2012;6:12-20.

136. Liu D-M, Troczynski T, Tseng WJ. Water-based sol-gel synthesis of hydroxyapatite: process development. Biomaterials. 2001;22:1721-30.

137. Song $Y$, et al. Electrodeposition of ca-P coatings on biodegradable mg alloy: in vitro biomineralization behavior. Acta Biomater. 2010;6:1736-42.

138. Arce JE, et al. Calcium phosphate-calcium titanate composite coatings for orthopedic applications. Ceram Int. 2016;42:10322-31.

139. Wang M-J, Chao S-C, Yen S-K. Electrolytic calcium phosphate/zirconia composite coating on AZ91D magnesium alloy for enhancing corrosion resistance and bioactivity. Corros Sci. 2016;104:47-60.

140. $\mathrm{Xu} \mathrm{L}$, et al. In vitro and in vivo evaluation of the surface bioactivity of a calcium phosphate coated magnesium alloy. Biomaterials. 2009;30:1512-23.

141. Lorenz C, et al. Effect of surface pre-treatments on biocompatibility of magnesium. Acta Biomater. 2009;5:2783-9.

142. Keim S, et al. Control of magnesium corrosion and biocompatibility with biomimetic coatings. J Biomed Mater Res B Appl Biomater. 2011;96:84-90.

143. Nguyen $\mathrm{H}$, et al. The effect of sol-gel-formed calcium phosphate coatings on bone ingrowth and osteoconductivity of porous-surfaced $\mathrm{Ti}$ alloy implants. Biomaterials. 2004;25:865-76.

144. Oyane A, et al. The formation of an antibacterial agent-apatite composite coating on a polymer surface using a metastable calcium phosphate solution. Biomaterials. 2006:27:3295-303.

145. Zhou R, et al. Amorphous calcium phosphate nanospheres/polylactide composite coated tantalum scaffold: facile preparation, fast biomineralization and subchondral bone defect repair application. Colloids Surf B Biointerfaces. 2014;123:236-45.

146. Roy M, Bandyopadhyay A, Bose S. In vitro antimicrobial and biological properties of laser assisted tricalcium phosphate coating on titanium for load bearing implant. Mater Sci Eng C. 2009;29:1965-8. 
147. Perez RA, Kim H-W, Ginebra M-P. Polymeric additives to enhance the functional properties of calcium phosphate cements. Journal of tissue engineering. 2012;3:2041731412439555.

148. Hesaraki S, et al. Rheological properties and Injectability of $\beta$-Tricalcium phosphate-hyaluronic acid/polyethylene glycol composites used for the treatment of Vesicouretheral reflux. Biomed Eng Res. 2013;1:40-4.

149. Lee $Y$, et al. Reduction of inflammatory responses and enhancement of extracellular matrix formation by vanillin-incorporated poly (lactic-coglycolic acid) scaffolds. Tissue Eng A. 2012;18:1967-78.

150. Van de Watering $F$, et al. Biodegradation of calcium phosphate cement composites, in Degradation of implant materials: Springer; 2012. p. 139-72.

151. Li H, Li J, Ye J. Construction and properties of poly (lactic-co-glycolic acid)/ calcium phosphate cement composite pellets with microspheres-in-pellet structure for bone repair. Ceram Int. 2016;42:5587-92.

152. Ishikawa K, et al. Non-decay type fast-setting calcium phosphate cement: composite with sodium alginate. Biomaterials. 1995;16:527-32.

153. Xu HH, Burguera EF, Carey LE. Strong, macroporous, and in situ-setting calcium phosphate cement-layered structures. Biomaterials. 2007;28:3786-96.

154. Geffers M, et al. Dual-setting brushite-silica gel cements. Acta Biomater. 2015;11:467-76.

155. Sopcak T, et al. Effect of phase composition of calcium silicate phosphate component on properties of brushite based composite cements. Mater Charact. 2016;117:17-29.

156. Verron $\mathrm{E}$, et al. Calcium phosphate biomaterials as bone drug delivery systems: a review. Drug Discov Today. 2010;15:547-52.

157. Li N, et al. Preparation of an rhBMP-2 loaded mesoporous bioactive glass/ calcium phosphate cement porous composite scaffold for rapid bone tissue regeneration. J Mater Chem B. 2015;3:8558-66.

158. Ruhe $P Q$, et al. rhBMP-2 release from injectable poly (DL-lactic-co-glycolic acid)/calcium-phosphate cement composites. JBJS. 2003;85:75-81.

159. Erbe $E$, et al. Potential of an ultraporous $\beta$-tricalcium phosphate synthetic cancellous bone void filler and bone marrow aspirate composite graft. Eur Spine J. 2001;10:S141-S6.

160. Erbe, E.M., et al. Biocompatible bone graft material. Journal 2007.

161. Ryu J, et al. Bone-like peptide/hydroxyapatite nanocomposites assembled with multi-level hierarchical structures. Soft Matter. 2011;7:7201-6.

162. Nouri-Felekori M, Mesgar AS-M, Mohammadi Z. Development of composite scaffolds in the system of gelatin-calcium phosphate whiskers/fibrous spherulites for bone tissue engineering. Ceram Int. 2015;41:6013-9.

163. Li Q, et al. A comparative evaluation of the mechanical properties of two calcium phosphate/collagen composite materials and their osteogenic effects on adipose-derived stem cells. Stem Cells Int. 2016;2016. https://doi. org/10.1155/2016/6409546.

164. Maeda $Y$, et al. Bone healing by sterilizable calcium phosphate tetrapods eluting osteogenic molecules. Biomaterials. 2013;34:5530-7.

165. Kozłowska J, Sionkowska A. Effects of different crosslinking methods on the properties of collagen-calcium phosphate composite materials. Int J Biol Macromol. 2015;74:397-403.

166. Hadisi Z, Nourmohammadi J, Mohammadi J. Composite of porous starchsilk fibroin nanofiber-calcium phosphate for bone regeneration. Ceram Int 2015;41:10745-54

167. Zhao L, Weir MD, Xu HH. An injectable calcium phosphate-alginate hydrogel-umbilical cord mesenchymal stem cell paste for bone tissue engineering. Biomaterials. 2010;31:6502-10.

168. Zhang $\mathrm{H}-\mathrm{X}$, et al. In vitro and in vivo evaluation of calcium phosphate composite scaffolds containing BMP-VEGF loaded PLGA microspheres for the treatment of avascular necrosis of the femoral head. Mater Sci Eng C. 2016;60:298-307

169. Trajano $V$, et al. Osteogenic activity of cyclodextrin-encapsulated doxycycline in a calcium phosphate PCL and PLGA composite. Mater Sci Eng C. 2016;64:370-5.

170. Koempel JA, et al. The effect of recombinant human bone morphogenetic protein-2 on the integration of porous hydroxyapatite implants with bone. Journal of biomedical materials research: an official journal of the Society for Biomaterials. The Japanese Society for Biomaterials, and the Australian Society for Biomaterials. 1998;41:359-63.

171. Nair AK, et al. Molecular mechanics of mineralized collagen fibrils in bone Nat Commun. 2013;4:1724

172. Okada M, Matsumoto T. Synthesis and modification of apatite nanoparticles for use in dental and medical applications. Jpn Dent Sci Rev. 2015;51:85-95.
173. Matsunaga K, et al. First-principles calculations of divalent substitution of Ca2+ in tricalcium phosphates. Acta Biomater. 2015:23:329-37.

174. Huang J, et al. In vitro assessment of the biological response to nano-sized hydroxyapatite. JMSMM. 2004;15:441-5.

175. Galea LG, et al. Bone substitute: transforming $\beta$-tricalcium phosphate porous scaffolds into monetite. Biomaterials. 2008;29:3400-7.

176. Kim HD, et al. Biomimetic materials and fabrication approaches for bone tissue engineering. Advanced healthcare materials. 2017;6:1700612.

177. Khalyfa A, et al. Development of a new calcium phosphate powder-binder system for the 3D printing of patient specific implants. JMSMM. 2007;18:909-16.

178. Chernousova S, et al. A genetically active nano-calcium phosphate paste for bone substitution, encoding the formation of BMP-7 and VEGF-A. RSC Adv. 2013:3:11155-61.

179. Pardun K, et al. Mixed zirconia calcium phosphate coatings for dental implants: tailoring coating stability and bioactivity potential. Mater Sci Eng C. $2015 ; 48: 337-46$

180. Barba A, et al. Osteoinduction by foamed and 3D-printed calcium phosphate scaffolds: effect of nanostructure and pore architecture. ACS Appl Mater Interfaces. 2017;9:41722-36.

181. $\mathrm{Xu} \mathrm{HH}$, et al. Calcium phosphate cements for bone engineering and their biological properties. Bone research. 2017:5:17056.

182. Bose S, Tarafder S. Calcium phosphate ceramic systems in growth facto and drug delivery for bone tissue engineering: a review. Acta Biomater. 2012;8:1401-21.

\section{Ready to submit your research? Choose BMC and benefit from:}

- fast, convenient online submission

- thorough peer review by experienced researchers in your field

- rapid publication on acceptance

- support for research data, including large and complex data types

- gold Open Access which fosters wider collaboration and increased citations

- maximum visibility for your research: over $100 \mathrm{M}$ website views per year

At $\mathrm{BMC}$, research is always in progress.

Learn more biomedcentral.com/submissions 